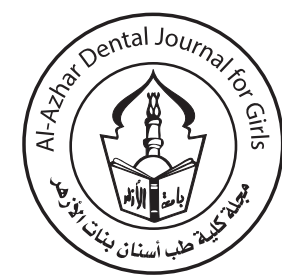

\title{
Comparison between Tracing Method and Cone Beam Imaging for Recording Bennett Movement
}

\author{
Sara M. Bahaa El-Din ${ }^{(1)}$, Mostafa M. Abd El-Ghany ${ }^{(2)}$, Amany A. Abd El-fattah ${ }^{(3)}$ \\ and Dina M. Kholief ${ }^{(4)}$
}

Codex : 04/1901

azhardentj@azhar.edu.eg

http://adjg.journals.ekb.eg

DOI: $10.21608 /$ adjg.2019.5591.1015

\begin{abstract}
Purpose: Was to compare between tracing method and Cone Beam imaging for recording Bennett movement and lateral condylar angle. Material and methods: Ten completely edentulous patients were selected with ages ranged from 50-60 years, with average age 55years. Each patient received complete denture and teeth were arranged according to balanced occlusion concept. The lateral condylar angle was measured by Gothic arch tracer and with Cone Beam imaging for each side. The Immediate Bennett shift was measured using condylar tracing and the Cone Beam imaging for each condyle during its lateral shift. Results: The result of this study showed that there was no significant difference between the Bennett angle measured by Gothic arch and the angle that get from Cone Beam and also there is no significant difference between the reading of immediate Bennett shift recorded by condylar tracer or Cone Beam. Conclusion: Within the limitation of this study, it can be concluded that, the Cone Beam recording can replace tracing method for recording Bennett angle and Bennett shift.
\end{abstract}

\section{INTRODUCTION}

The purpose of the guidelines for good occlusal practice is to reduce the risk of damage that might occur to the related tissues of the masticatory system, leading to increase the chances of a healthy function. This will reduce the liability to supporting tissue disease, mechanical failure of the denture and TMJ dysfunction or pain. Dentists can positively influence these factors as part of their care ${ }^{(1)}$.

\section{KEYWORDS}

Bennett shift,

Bennett angle,

Occlusion,

Complete Denture.

\footnotetext{
- Paper extracted from Doctor Thesis titled "Comparison between Tracing Method and Cone Beam Imaging for Recording Bennett Movement"

1. Assistant Lecturer of Removable Prosthodontics, Faculty of Dental Medicine for Girls, Al-Azhar University

2. Professor of Removable Prosthodontics,Dean of Faculty of Dental Medicine for Girls, Al-Azhar University

3. Professor of Removable Prosthodontics,Vice Dean of Faculty of Dental Medicine for Girls, Al-Azhar University.

4. Assist. Professor of Removable Prosthodontics, Faculty of Dental Medicine for Girls, Al-Azhar University.
} 
It has been established that, complete dentures exhibit different biomechanical characteristics than natural teeth. The denture acts as one unit, so that any force applied to any part of the denture tooth will be directly transferred to the entire denture. This limitation can be overcome by several occlusal concepts for complete dentures ${ }^{(2,3)}$.

Balanced occlusion is a favored occlusal scheme for setting denture teeth for the conventional complete dentures. It helps to preserve the supporting residual ridge and enhance the stability of dentures. Balanced occlusion provides teeth contacts at the working side as well as at the balancing side, at the same time ${ }^{(4)}$. Balanced occlusion in complete dentures is unique. If it occurs in natural teeth, it is considered interference at the nonworking side and should be adjusted ${ }^{(5)}$.

Lateral movement of the mandible is the grinding movement. It is responsible for chewing food during eating. It is divided into the balancing and working sides in human studies. The balancing condyle moves downward, forward and medially, it is known as the balanced side (the side the mandible moves away from). If it moves laterally it is called the working side ${ }^{(6)}$.

Bennett shift, it is the bodily lateral movement of the mandible occurs during lateral excursions ${ }^{(7)}$. Bennett movement occurs in medio-lateral direction and is limited by the temporomandibular ligament ${ }^{(8)}$. Bennett noticed the lateral shift in the position of the working condyle (the side which the mandible moves towards), he noted that, when the mandible was moved bodily to one side, the condyle on this side rotated in its place or moved slightly lateral, and the opposite condyle the balancing condyle moved downward and forward ${ }^{(9)}$.

The Bennett movement is directly proportional to the side lateral shift. The analysis of Bennett movement shows its effects on occlusal morphology of the teeth, it was found that, the bigger the side lateral shift, the more distal will be the working and balancing sulcus in the upper teeth, and the more lower will be the cusps of the posterior teeth, and the greater will be the over jet of the anterior teeth ${ }^{(10)}$.

\section{MATERIAL AND METHODS}

The clinical study made on ten completely edentulous patients. The patients were selected to have their ridges covered with firm, thick and compressible mucosa, free from any signs TMJ disorder. Patients with clicking, TMJ tenderness on palpation, limitation of opening or mandibular movement, muscle spasm or tenderness, mandibular deviation, TMJ pain on assisted opening and crepitus were excluded. All patients accepted this dental treatment and informed about the steps of this study and signed a written consent with the Research Ethics Committee (REC) approval.

\section{Steps of complete denture construction:}

For each patient primary impression for upper and lower ridges were made using stock tray with suitable size and alginate as primary impression material. Final impression were made using autopolymerizing acrylic resin special trays which were traced using green stick compound and zinc oxide and eugenol as final impression material.

Maxillomandibular relations records were made using auto-polymerizing acrylic resin for upper and lower trial denture bases and modeling wax occlusion rims were constructed.

Face-bow record was made using Hanau spring bow. The maxillary cast was mounted to the upper member of the articulator using plaster.

The centric relation record was recorded using interocclusal wax record. The wax record that used for centric relation registration was separated from the lower record block and was kept in cold water.

Protrusive record registration two layers of softened wax were added to the lower record block. The patient was instructed to protrude the mandible about $6 \mathrm{~mm}$ and close his mouth. The wax record 
used for protrusive relation registration was separated from the lower record block and was kept in cold water.

Mounting of the mandibular cast, the articulator used was Hanau $96 \mathrm{H} 2$ semi-adjustable articulator The lower cast was mounted to the lower member of the articulator using centric relation record wax and plaster.

Adjustment of the condylar guidance: horizontal condylar guidance of the articulators was adjusted according to the protrusive record. The lateral condylar guidance of both sides obtained from Hanau equation $\mathrm{L}=\mathrm{H} / 8+12$.

Anatomical teeth were used for teeth setting. Teeth were aligned to balanced articulation. Denture was waxed up, tried at the patient mouth and processed into heat cured acrylic resin.

Clinical remounting: occlusal adjustment of the finished denture using new face bow, centric, protrusive and lateral records without teeth contact and any occlusal disharmony was eliminated.

\section{Registrations of the lateral condylar angles using Gothic arch:}

The carrier of the Gothic arch was attached to the occlusal surface of the lower record block; the tracing plate was attached to the occlusal surface of the upper record block. The tracing point was adjusted at the patient's mouth to keep the occlusal surface of upper and lower record blocks slightly apart.

The patients were guided to perform protrusive, retrusive and lateral excursions while the tracing point was kept in contact with the tracing plate. The upper record block was removed and the plate was painted with thin film of the wax. The upper record block was replaced at the patient's mouth and the patient was asked to perform protrusive-retrusive, right-retrusive and left- retrusive movements. The upper and lower record blocks were removed from the patient's mouth and the tracing over the tracing plate was examined. The arrow that was traced should be clearly identified to record lateral condylar path.

The tracing arrow over the tracing plate was scanned and printed by the computer. The right and left angels between the protrusive and lateral right and left condylar paths were measured using the protractor to the nearest 0.5 degree. The right and left lateral condylar guidance were derived from the following formula $\mathrm{L}=1.06 \mathrm{BP}-45$. Where $\mathrm{L}$ was the lateral condylar angle and $\mathrm{BP}$ was the angle between the lateral borders paths of the patient and the protrusive path.

\section{Graphic tracing of immediate Bennett shift:}

The bite fork of the Quick set recorder was attached to the lower record block fixed to the mandible by mandibular clamp. Apiece of recording paper was attached to each flag. The patient was seated in an upright, comfort position with the jaw in the most retruded position. The patient was instructed to move his jaw from the most retruded position to the right side to record the immediate side shift. (Fig. 1) The amount of immediate side shift was indicated on the assembly scale by the amount of pointer movement in $\mathrm{mm}$ using the digital caliper. Similarly, the patient's jaw was moved to the left side to record the immediate and progressive side of the right condyle.

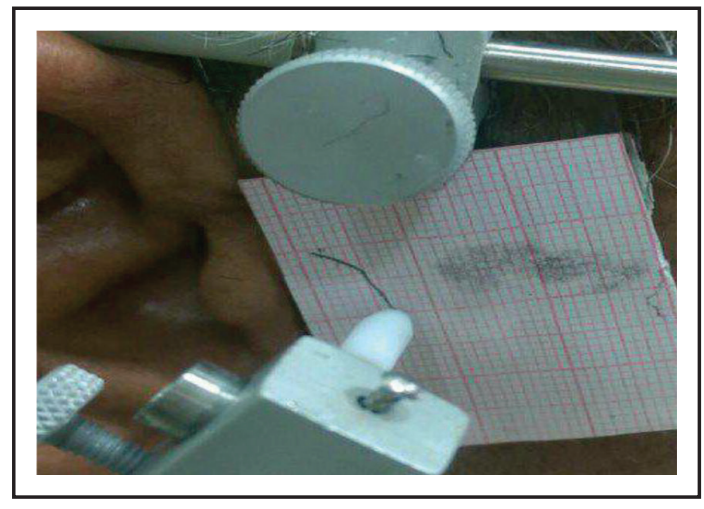

Fig. (1) Immediate Bennett shift 


\section{Cone beam scanning}

CBCT Planmeca machine was used at the study. The patient was placed on the machine and FOV was adjusted guided by laser lines. Cone beam CT was taken to the patient in centric and lateral positions.3D images the outline of condyles in both centric and eccentric positions are digitally delineated.

For each condyle of each patient, radiograph in centric and lateral working were superimposed (Fig. 2). For each patient the centric and lateral balancing condyle images were super imposed (Figure 3 ). The lateral condylar path was obtained for the balancing condyle by drawing a line tangent to the condyle in maximum intercuspation and in lateral position.

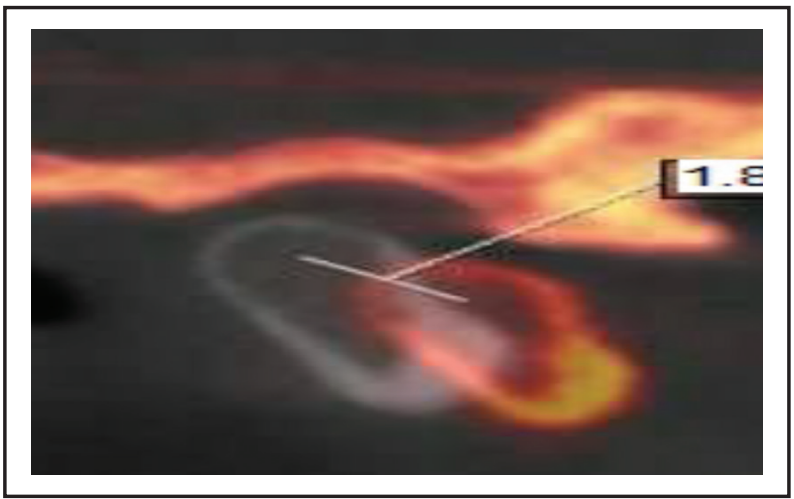

Fig. (2) Centric and working condyle superimposition

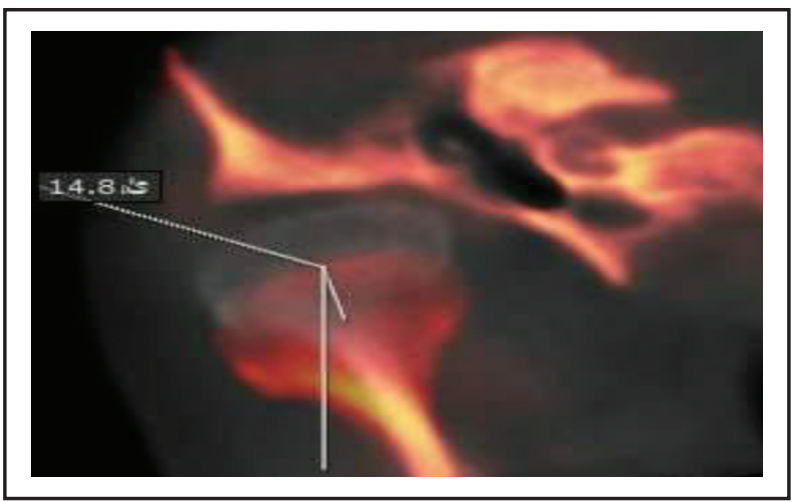

Fig. (2) Centric and balancing condyle superimposition.

The angle between the lateral condylar path and sagittal plane was measured. This procedure was made twice for each balancing condyle of the same patient and the mean angle was obtained and tabulated. For the working condyle, the Bennett movement was measured by measuring the amount of working condyle movement laterally from the centric relation to the lateral position. The previous procedure was made twice for each working condyle of the same patient and the mean of these measurements were obtained and tabulated.

\section{Statistical analysis}

All measurements were recorded and tabulated. Statistical analysis was then performed using a commercially available software program (SPSS 19; SPSS, Chicago, IL, USA). Paired t test was used to compare Gothic arch reading and reading from Cone Beam for lateral condylar angle. The Paired $t$ test used to compare between reading from condylar tracer and Cone Beam imaging for immediate Bennett shift.

\section{RESULTS}

Comparison between lateral condylar angle records with condylar Gothic arch and Cone Beam revealed that the mean difference for the right side was 0.1 , the standard deviation difference was 3.82 and the $\mathrm{P}$ value was 0.844 . The $\mathrm{P}$ value for the right side was $>0.005$ means there was no significant difference between Gothic arch reading and reading from Cone Beam. The mean difference for the left side was 0.48 , the standard deviation difference was 0.2 and the $\mathrm{P}$ value was 0.23 . The $\mathrm{P}$ value for the left side was $>0.005$ means there was no significant difference between Gothic arch reading and reading from Cone Beam. (table. 1)

Comparison of Immediate side shift measurements with condylar tracer and Cone Beam revealed that the mean difference for the right side was 0.115 , the standard deviation difference was 0.25 , the value of $t$ was -0.471 and the $P$ value was 0.694 . The $\mathrm{P}$ value for the right side was $>0.005$ means there was no significant difference between condylar tracer reading and reading from Cone Beam. The mean difference for the left side was 0.3 , the standard deviation difference was 0.06 the value of 
Table (1) Comparison of gothic arch reading (in degree) and Cone Beam reading for lateral condylar angle using Paired t test.

\begin{tabular}{|c|c|c|c|c|c|c|c|}
\hline \multicolumn{4}{|c|}{ Right side } & \multicolumn{4}{c|}{ Left side } \\
\hline $\mathrm{Md}^{*}$ & SDd** & t-value & P-value & Md & + SDd & t-value & P-value \\
\hline 0.1 & 3.82 & -0.20203 & $0.8449 \mathrm{~ns}$ & 0.48 & 0.2 & -1.27566 & $0.234016 \mathrm{~ns} * * *$ \\
\hline
\end{tabular}

$* M d=$ Mean difference $\quad * * S D d=$ standard deviation deference $\quad * * * n s=$ non significant.

Table (2) Comparison of Immediate Bennett shift measurements (in mm.), for records made with condylar tracer and Cone Beam using Paired t test.

\begin{tabular}{|c|c|c|c|c|c|c|c|}
\hline \multicolumn{4}{|c|}{ Right side } & \multicolumn{4}{c|}{ Left side } \\
\hline Md* & SDd** & Md* & SDd** & Md* & SDd** & Md* & SDd** \\
\hline 0.115 & 0.25 & 0.115 & 0.25 & 0.115 & 0.25 & 0.115 & 0.25 \\
\hline
\end{tabular}

$* M d=$ Mean difference. $\quad * * S D d=$ Standard deviation difference. $\quad * * * n s=$ Non-significant.

$\mathrm{t}$ was -1.57 and the $\mathrm{P}$ value was 0.153 . The $\mathrm{P}$ value for the left side was $>0.005$ means there was no significant difference between condylar tracer reading and reading from Cone Beam. (table. 2)

\section{DISCUSSION}

Balanced occlusion can help in better chewing efficiency, maintaining the stability of the denture and ensure even pressure on the residual ridge ${ }^{(11)}$. Bennett angle has a very high gnathological importance since its presence and size affects the occlusal relationships of denture fabrication ${ }^{(12)}$. During treatment of edentulous patients, graphic registering technique is recommended to verify the centric relation and to record the condylar guidance. So the lateral border paths produced by the intra-oral needle point tracing techniques were used for determination of the lateral condylar guidance following the Eichold formula ${ }^{(13)}$.

Although the Gothic arch methods have been used to record centric relation and condylar guidance but there are certain disadvantage of this technique. Certain limitations of the Gothic arch technique including the effect of tissue resiliency, it requires good ridge anatomy, stable denture bases, sufficient inter ridge dimension, patient co-operation and neuromuscular coordination, experienced dentist and this method is time consuming. ${ }^{(14)}$ The Gothic arch technique was found to be sensitive, there is greater chance of errors due to mishandling of the device, and fatigue of muscles and jaws from repeated efforts to guide the mandibular movements to produce correct arrow head tracing ${ }^{(14)}$.

The computed tomography has been already used in the evaluation of the Bennett angle, however, its application has been only used for the measuration of the angle without any other clinical use. So there is a controversy for the measurements of Bennett movement recorded by tracing method and by $\mathrm{x}$-ray imaging ${ }^{(12)}$.

The Bennett movement can be studied in detail by a pantographic registration, which shows that it consists of two movements: the immediate Bennett side-shift which occurs at the beginning of the translation, and the progressive Bennett side shift. In the immediate Bennett side shift, the orbiting condyle moves essentially straight medially as it leaves centric relation at the beginning of the lateral jaw movement ${ }^{(15)}$. In the present study the Bennett movement was measured by tracing method 
depending on previous state, which measured the distance the orbiting condyle moved as it leaves the centric relation moving straight medially.

The development at the diagnostic imaging technology occurs during the last few years especially at the computed tomography. This allows us to get benefit from measurement methods of absolute precision and able to perform morphological and highly detailed studies. The measurement of a parameter such as the Bennett angle and movement are greatly important for right prosthetically and gnathological rehabilitation. The $\mathrm{CT}$ volumetric acquisition always gives complete information about the bone and dental structures of the masticatory apparatus (16). The centric relation, the right laterality and the left laterality were determined. In the present study the Cone Beam images was used for recording Bennett angle and movement.

\section{CONCLUSION}

Within the limitation of this study, it can be concluded that, the Cone Beam recording can replace tracing method for recording Bennett angle and Bennett shift.

\section{REFERENCES}

1. Davies S, Gray R. Occlusion: What is occlusion? Br Dent J 2001;191:235-45.

2. Hobrink J, Zarb GA, Eckert S, Jacob R. Prosthodontic treatment for edentulous patients: Complete dentures and implant-supported prostheses. $13^{\text {th }}$ ed: St Louis: Elsevier Mosby; 2012: 204-29 .

3. Abduo J. Occlusal schemes for complete dentures: a systematic review. Int J Prosthodont 2013;26:1-15.

4. Poštić SD. Influence of balanced occlusion in complete dentures on the decrease in reduction of an edentulous ridge. Vojnosanit Preg1 2012;69:1055-60.

5. Rangarajan V, Gajapathi B, Yogesh P, Ibrahim MM, Kumar $\mathrm{RG}$, Karthik P. Concepts of occlusion in prosthodontics: A literature review, part I. J Indian Prosthodont Soc 2015; 15:200.
6. Fang J-J, Kuo T-H. Modelling of mandibular movement. Comput Biol Med 2008;38:1152-62.

7. Choi K-Y, Yang J-D, Chung H-Y, Cho B-C. Current concepts in the mandibular condyle fracture management part I: overview of condylar fracture. Arch Plast Surg 2012;39:291-300.

8. Koolstra JH, van Eijden TM. Three-dimensional dynamical capabilities of the human masticatory muscles. Journal of biomechanics 1999;32:145-52.

9. Zakaria MR.Acomparison between the horizontal condylar and bennett angles of iraqi full mouth rehabilitation patients by using two different articulator systems: an invivo study. JBCD 2016;28:26-35.

10. Bhawsar SV, Marathe AS, Ansari SA. Evaluation of Hanau's formula in determination of lateral condylar guidance: A clinical research study. J Indian Prosthodont Soc 2015; 15:326-9.

11. Peroz I, Leuenberg A, Haustein I, Lange K-P. Comparison between balanced occlusion and canine guidance in complete denture wearers--A clinical, randomized trial. Quintessence Int J 2003;34:8-15.

12. Fanucci E, Spera E, Ottria L, Barlattani A, Jr., Fusco N, Mylonakou I, et al. Bennett movement of mandible: a comparison between traditional methods and a 64-slices CT scanner. Oral Implantol 2008;1:15-20.

13. Abdel-Ghany M. The effect of horizontal and lateral condylar path inclination records on complete denture balancing occlusion.: Al-azhar Univ2003.

14. Thakur M, Jain V, Parkash H, Kumar P. A comparative evaluation of static and functional methods for recording centric relation and condylar guidance: A clinical study. J Indian Prosthodont Soc 2012;12:175-81.

15. Stiesch-Scholz M,Demling A, Rossbach A. Reproducibility of jaw movements in patients with craniomandibular disorders. J Oral Rehabil 2006;33:807-12.

16. Sommer OJ, Aigner F, Rudisch A, Gruber H, Fritsch H, Millesi W, et al. Cross-sectional and functional imaging of the temporomandibular joint: radiology, pathology, and basic biomechanics of the jaw. Radiographics : a review publication of the Radiological Society of North America, Inc 2003;23:14-22. 